\title{
3D Miniature Antenna Design for RFID Applications in loT Environment
}

\author{
A.Nasir Mohamed ${ }^{1,{ }^{*}}$, S.N Azemi ${ }^{2}$, S.A Suhaimi ${ }^{2}$, and A.A.M. Ezanuddin ${ }^{2}$ \\ ${ }^{1}$ School of Computer and Communication Engineering, Universiti Malaysia Perlis (UniMAP), Perlis, \\ Malaysia. \\ ${ }^{2}$ Advanced Communication Engineering Centre (ACE), UniMAP, Perlis, Malaysia
}

\begin{abstract}
The antenna application for internet of things (IoT) in urban infrastructure is introduced. Here, an effective design of microstrip 3D antenna for a RFID system in IOT which can also be used in narrow-band wireless communication is proposed. The antenna is combination of meander line techniques implemented with $3 \mathrm{D}$ structure resulted to miniature size of antenna that will be useful in many application. The critical parameters analysis and simulation results demonstrate the validity of the antenna with high gain and impedance matching are discussed as well.
\end{abstract}

\section{Introduction}

The Internet of Things (IoT) is an environment that has capability to transfer data over a network without needing human-to-human or human-to-computer interaction. IoT has developed from the convergence of wireless technologies, micro-electromechanical systems (MEMS) and the Internet. Furthermore is a global social network infrastructure based on normal and communication interoperable protocols where real and virtual "things" have unique characteristics, real quality, and particular personalities [1]. Recently, IoT are predictable to become active contributors in business, social processes and information where they are allowed to cooperate and communicate between themselves and with the surroundings by replacing information and data senses about the environments, while responding independently to the "real /physical world" events influence it by consecutively processes that start create services and actions with or not including direct human being interference [2]. IoT will extend abilities of conventional and localized exploitation of automatic identification and data capture and other interfacing technologies. As prospective new technology IoT has great potential applications in the administration of urban infrastructure [3].

With the Internet of Things (IoT), everything will be wireless. The physical connection for many IoT hubs leverages legacy wired system found in homes, workplaces, schools, industrial facilities and other areas. All the 'things' such as bag, cloth, shoes, glasses, could be connected to the internet and will communicate. Nevertheless, in order to become the ultimate mobile information sensing platform, a powerful and robust antenna is required.

\footnotetext{
*Corresponding author: nasir121080079@gmail.com
} 
Every wireless connection needs at least two antennas which is one for transmitter (Tx) and one for receiver $(\mathrm{Rx})$.

RFID (Radio frequency identification) is a word that is used to describe a system that transmits the identity of an object, goods or person wirelessly or using radio waves [4]. Technology of radio communication was rapid growth in last 10 years and improves their performance in order to make it smaller, cheaper and reliable. A basic component of RFID is RFID tags, readers or antenna and transceiver. Small antenna will be easier to apply in any application of the latest technologies which is demanded by other sector and attraction from antenna designer. There are several technique to reduce the antenna size such as meander line and fractal design beside, using specific higher permittivity substrate will also decrease the antenna size as well as the bandwidth due to the attentiveness involving the actual power field in the higher permittivity locations. However, by reducing the size of the antenna will be increased unwanted radiation because of the unbalance current which appear on the small ground plane. There are mostly occurring from the ground plane and the input connector part.

Nowadays antenna miniaturization becomes one of the research focuses, owing to the limitation of size of RFID card. In the present paper, Hilbert fractal theory and technique are employed to achieve the goal of reduction dimension of tag antenna. Additionally, in order to improve antenna efficiency, the impedance matching of the antenna must be considered [5]. It is known that the input impedance of IC chip varies from manufacturer to manufacturer. Generally speaking, the tag antenna is requested to directly match to IC chip. This is to say, the input impedance of tag antenna can be adjusted flexibly to realize impedance matching. To solve this problem, meander line technique is applied in our work. Simulations indicate that the value of input impedance of tag antenna can be changed readily by tuning the high line.

Here, microstrip meander line $3 \mathrm{D}$ antenna operating at $2.45 \mathrm{GHz}$ for IoT environment is described. Recent technology 3D antenna is believed to overcome some of the drawbacks identified in conventional antennas where it is required for certain application. The design and simulation processes are done by using CST Microwave Studio. The simulation result is optimized to achieve the best performance of the antenna. All manuscripts must be in English, also the table and Fig. texts, otherwise we cannot publish your paper.

\section{Antenna design and analysis}

Antenna structure shown in Fig. 1 until Fig. 4 shows the proposed antenna designed. The antenna is mounted in the middle of a rectangular ground plane with the dimension of $21.6 \mathrm{~mm} \times 21.6 \mathrm{~mm}$. Originally, the size of antenna was determined by $\lambda / 4$. The width of the antenna was calculated by:

$$
\lambda=\frac{c}{f}
$$

Where;

Calculation:

$\lambda=$ wave length, $c=$ speed of light, $f=$ frequency

$$
\lambda=\frac{3 \times 10^{8}}{2.45 G H z}=0.1224 m
$$

With the meander line technique implemented with 3D structure, each arm of the antenna $\mathrm{L}_{2}$ is $4.3 \mathrm{~mm}$. The antenna size is reduced to $\frac{\lambda}{30}$. Table 1 shows the antenna size and parameter. 
Table 1. 3D Antenna's Parameters.

\begin{tabular}{|c|c|c|}
\hline Parameters & Description & Value $[\mathrm{mm}]$ \\
\hline$L$ & Length of the ground plane & 21.6 \\
\hline$W$ & Width of the ground plane & 21.6 \\
\hline$L_{1}$ & Length of the antenna & 4.3 \\
\hline$L_{2}$ & Length of the antenna & 2.15 \\
\hline
\end{tabular}

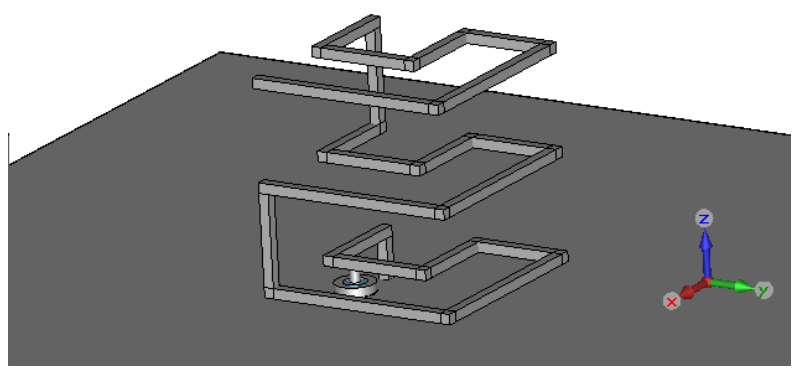

Fig. 1. Perspective Top View of 3D Antenna.

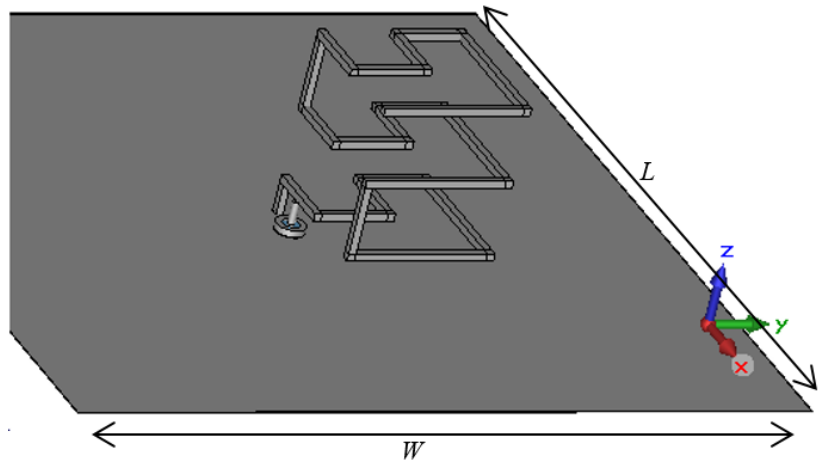

Fig. 2. The proposed 3D Antenna. 


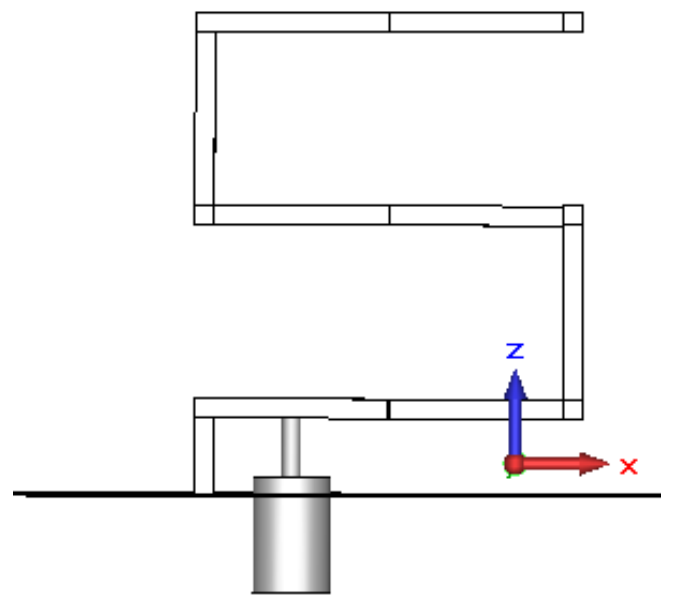

Fig. 3. Side View of the 3D Antenna.

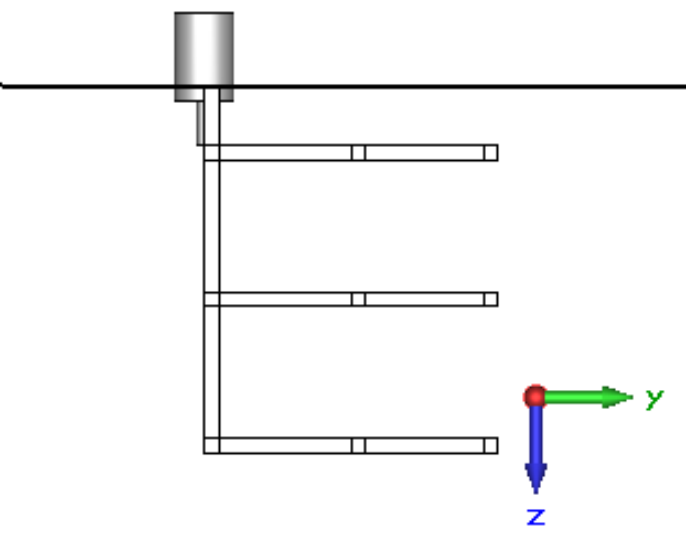

Fig. 4. Bottom View of 3D Antenna.

\section{Simulation results}

The return loss and fabricated antenna for the optimized dimension as given in Table 1 is shown in Fig. 5. The Fig. shows the minimum return loss is $-20 \mathrm{~dB}$ operating at the frequency of $2.45 \mathrm{GHz}$. From the Fig., it is clearly observed that the proposed 3D meander line antenna covers the frequency range from $2.447 \mathrm{GHZ}$ to $2.459 \mathrm{GHz}$ for return loss $-10 \mathrm{~dB}$. Hence, the impedance bandwidth of this antenna is $0.012 \mathrm{GHz}$ that is Equivalent to $0.48 \%$ at the center frequency.

Other importance performance parameters of the antenna are radiation patterns. There are 3 information that can be retrieve from the radiation pattern which is efficiency, gain and directivity. Shown in Fig. 6 until 8 are the radiation pattern results in 3D as well in 2D. As can be seen, at frequency $2.45 \mathrm{HGz}$, the radiation pattern indicates an Omni directional radiation pattern and the far field gain of the antenna are $2.69 \mathrm{~dB}$. Main lobe direction of the direction 
is 103 degrees. The angular width at the $3 \mathrm{~dB}$ points of the main lobe is 95.3 degrees that a wider and suitable for good performance antenna.

Efficiency can be measured by bringing in the entire power flux. The efficiency of this antenna are $-0.5 \mathrm{~dB} / 89 \%$. Antenna gain is the main performance which combined the antenna directivity and electrical efficiency. Directivity is probably the standard antennas in fact it is way of measuring type of radiation or directional pattern. The directivity of this antenna is $1.28 \mathrm{~dB}$ at $2.45 \mathrm{GHz}$.

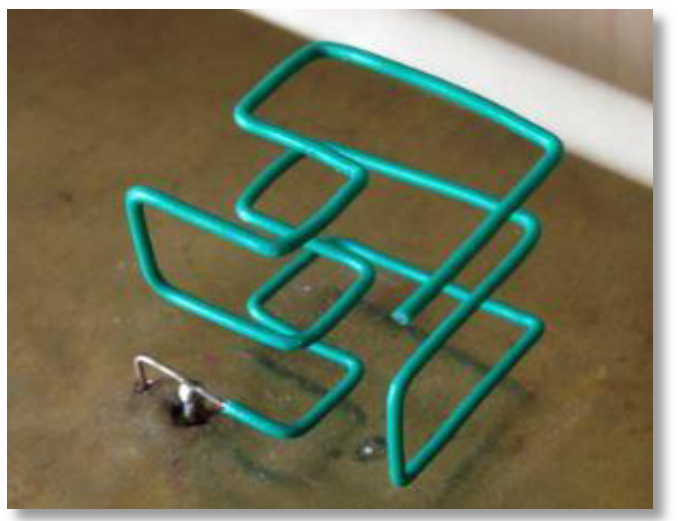

Fig. 5. (a) Fabricated 3D miniature antenna.

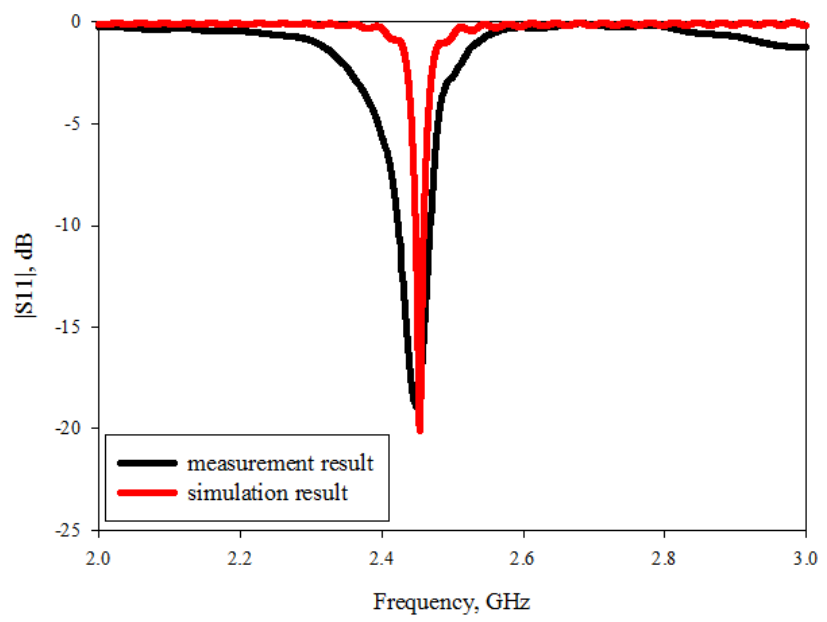

Fig. 5. (b) $\left|S_{11}\right|$ Antenna results. 


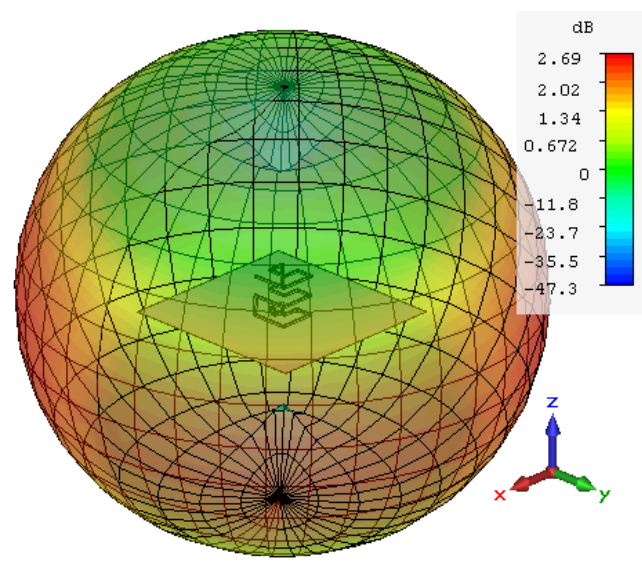

Fig. 6. 3D Antenna Radiation.

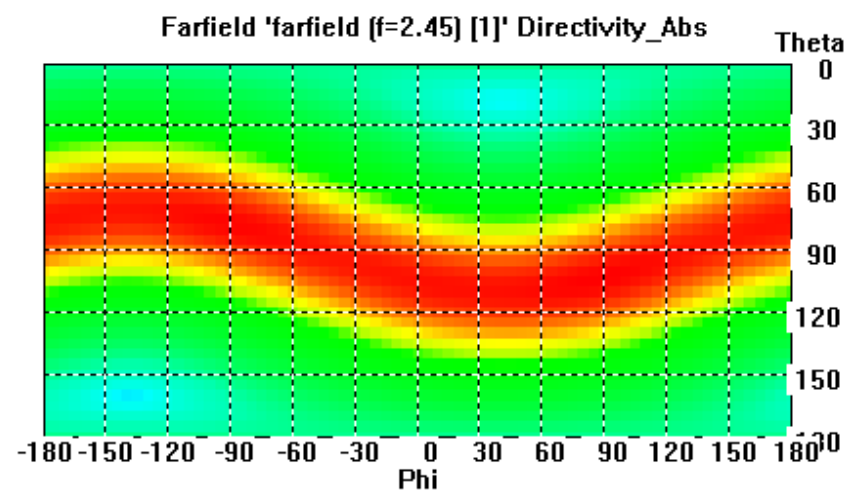

Frequency $=2.45$

Rad. effic. $=\mathbf{- 0 . 0 4 7 1 4 8 4 \mathrm { dB }}$

Tot. effic. $=\mathbf{- 0 . 4 6 1 2 6 2 \mathrm { dB }}$

Dir. $=1.74283 \mathrm{dBi}-38.3 \quad 1.74 \mathrm{dBi}$

Fig.7. 2D Antenna Radiation Pattern.

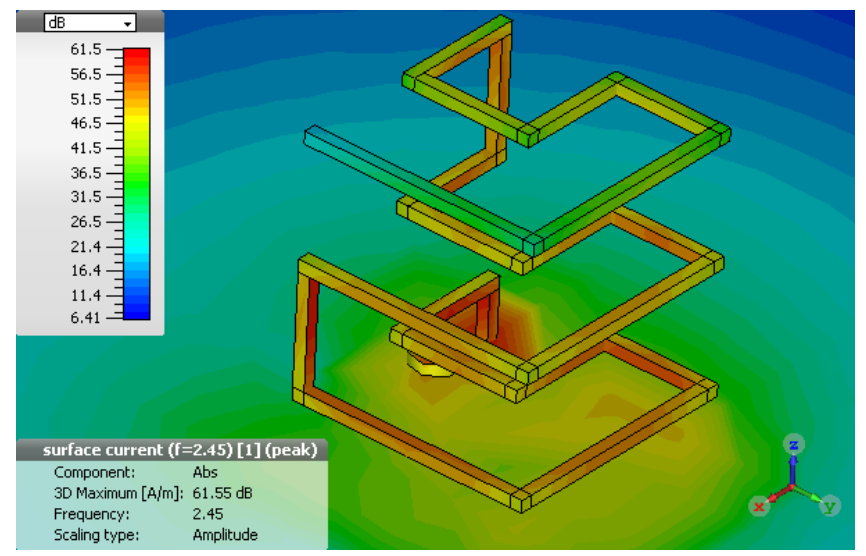

Fig. 8. Surface Current of the Antenna. 


\section{Conclusion}

In this paper, we proposed a miniature $3 \mathrm{D}$ antenna operating at $2.45 \mathrm{GHz}$ that consists of meander line technique with perfect electric conductor (PEC). By implementing meander lines techniques in $3 \mathrm{D}$ structure, the antenna enable to reduce it size up to $1 / 30 \lambda$. The final design occupies a small area of $4.3 \mathrm{~mm} \times 4.3 \mathrm{~mm}$. It is not only small in size, but yet has < $90 \%$ efficiency with relatively gain. With these entire properties make this antenna is a good choice in compact antenna application for IoT in urban infrastructure. Miniaturized scale able to be integrated with WLAN Access points, 3G Routers (either internally or externally), mobile/smart phones, mobile devices (PDA, laptop, Tablets etc).

\section{References}

1. Y. Chen, D. Zeng, T. Tang, Antenna Design for IOT in Urban Infrastructure, Journal of Convergence Information Technology, 8, (2013)

2. S. Erumal, N.M. Norwawi, V. Raman, In Digital Information Processing and Communications (ICDIPC), 2015 Fifth International Conference, (2015)

3. Y. Chen, Applied Mechanics and Materials, (2013)

4. V.D. Hunt, A. Puglia, M. Puglia, RFID: A Guide To Radio Frequency Identification, John Wiley \& Sons, (2007)

5. Z. Katbay, S. Sadek, R. Lababidi, A. Perennec, M. Le Roy, In New Circuits and Systems Conference (NEWCAS), IEEE 13th International, (2015) 